\title{
Flextensional Ultrasonic Motor Using the Contour Mode of a Square Piezoelectric Plate
}

\author{
Joni T. Leinvuo, Stephen A. Wilson, and Roger W. Whatmore
}

\begin{abstract}
This paper presents the design, fabrication, and characterization of a new type of standing wave piezoelectric ultrasonic motor. The motor uses a metallic flextensional amplifier, or cymbal, to convert the contour mode vibrations of a square piezoelectric ceramic plate into flexural oscillations, which are further converted to produce rotary actuation by means of an elastic-fin friction drive. The motor operates on a single-phase electrical supply. A beryllium copper rotor design with three-fin configuration was adopted, and the geometry was varied to include different material thicknesses, fin lengths, and inclinations. The best stall torque and no load speed for a 25-mm square motor were $0.72 \mathrm{Nmm}$ and $895 \mathrm{r} /$ minute, respectively. The behavior of the stator structure was analyzed by ANSYS finite element software using harmonic and modal analyses. The vibration mode estimated by finite element modeling (FEM) was confirmed by laser Doppler vibration measurements.
\end{abstract}

\section{INTRODUCTION}

$\mathrm{U}$ LTRASONIC motors [1] have many advantages for applications in microelectromechanical systems (MEMS). In contrast with electromagnetic motors, their simple construction makes them well suited for miniaturization, and their overall efficiency is relatively insensitive to size.

The study reported here focuses on a standing wavetype motor of very simple design that combines the contour mode vibrations of a piezoelectric ceramic plate with a metallic flextensional amplifier/mode converter to turn the contour vibrations into vertical motion perpendicular to the plane of the plate. The beryllium copper rotor uses the elastic fin principle of operation that was described in [2] and is illustrated in Fig. 1. Elastic fins connected to a rotor are pushed into contact with a vibrating surface. As the vibrating element moves upward (I $\rightarrow$ II $\rightarrow$ III) (along the z-axis), the tip of each fin is held in contact with its surface by static friction. The fins act as rigid levers, and the rotor is propelled about its axis of rotation by the horizontal component of the reactive force. When the vibrating element moves downward (IV $\rightarrow \mathrm{V} \rightarrow \mathrm{VI}$ ), the tips of the fins slip across its surface and so the cycle progresses back to I.

Manuscript received March 22, 2003; accepted March 11, 2004. The authors gratefully acknowledge the financial support of the Engineering and Physical Sciences Research Council (EPSRC) grant number GR/N 34017 and BAeSystems (Sowerby Research Center).

The authors are with Cranfield University, School of Industrial and Manufacturing Science, Cranfield, Bedfordshire, UK. (e-mail: jleinvuo@cc.hut.fi,r.w.whatmore@cranfield.ac.uk)

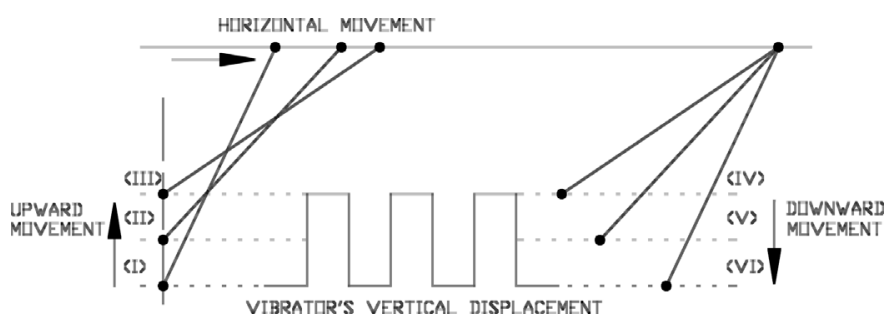

Fig. 1. Schematic of an elastic fin and the sequence of operation [2].

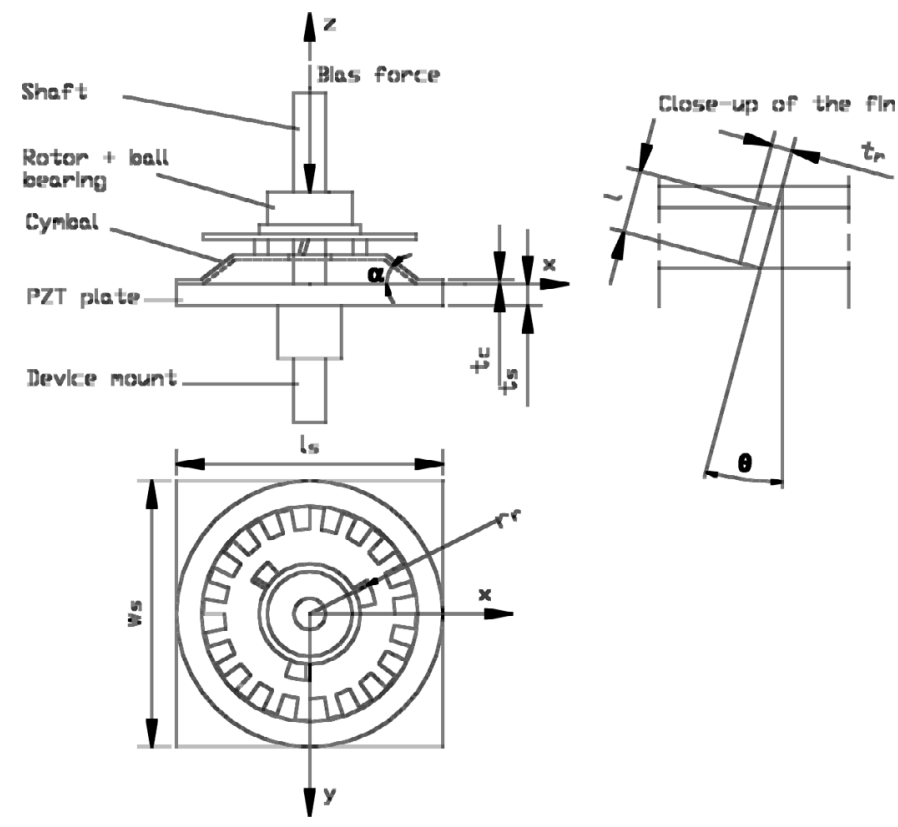

Fig. 2. Schematic of the flextensional motor construction.

A beryllium copper flextensional amplifier or cymbal [3], [4] converts the contour vibrations ( $\mathrm{x}-\mathrm{y}$ plane) of a square piezoelectric plate into vertical flexural oscillations along the direction normal to its plane (z-axis). The elastic fin coupling elements are pressed into contact with the upper surface of the cymbal, as illustrated in Fig. 2.

The cymbal operates both as a mode conversion element and displacement amplifier. In this way the relatively high force generated by the piezoelectric transducer (PZT) element can be better matched for motor use. Previous work [5]-[7] has demonstrated a motor of this type using a double cymbal arrangement with a circular disc PZT driver. The motor design described here is simpler because the structure is single sided and better matched 
TABLE I

Practical Design Parameters for Rotors and Stator.

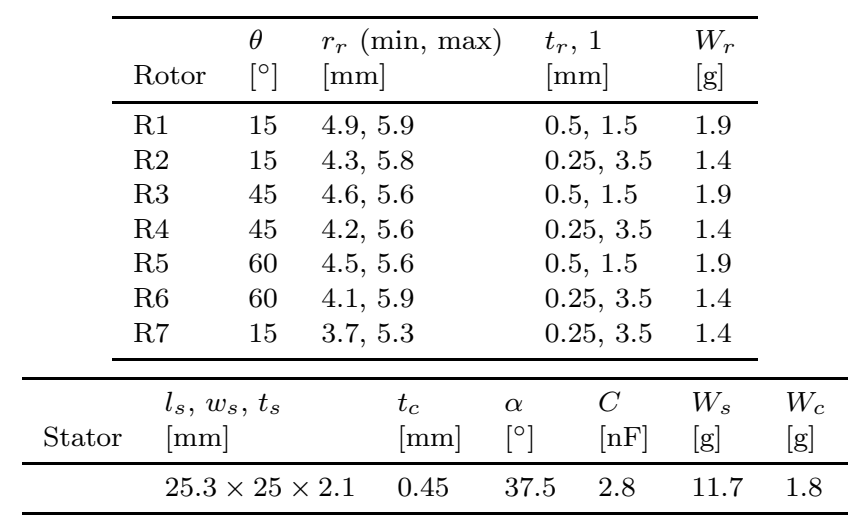

to MEMS manufacturing processes, for which the motor designed here was a scaled-up prototype. Especially the square plate as a vibrating element is expected to give advantages in matrix-based MEMS processes because dicing out of the devices could be made by standard semiconductor saw. The motor is attached at the plate's center point to allow free contour movement of the PZT driver. A spring load (bias force) is applied to press the fins into contact with the cymbal, and some lateral movement is allowed at the shaft to ensure even contact. The motor operates on a single-phase electrical supply. This gives some advantages of simplicity when compared with the complicated multiphase drives frequently used with travelling-wave motors. The motor is unidirectional. Two-way operation could perhaps be achieved by a double-fin configuration in which two sets of fins with inverted angles are located at the different radii [6].

\section{DESIGN}

In operation, the vertical displacement of the cymbal surface is in direct relation to the radial displacement of the cymbal's contact ring. The parameters relevant to the motor design are defined in Fig. 2 and Table I. In this design, $\theta$ is the angle of the fin and $r_{r}$ is the rotor/stator contact radius; $l$ and $t_{r}$ are length and thickness of the fin, respectively. $W_{r}$ is weight of the rotor, including ball bearing $(0.94 \mathrm{~g}) ; l_{s}, w_{s}$, and $t_{s}$ are the length, width, and thickness of the PZT element; $\alpha$ and $t_{c}$ are the cymbal's wall angle and thickness, respectively. $W_{s}$ and $W_{c}$ are the weight of the stator and the cymbal; $C$ is the low frequency capacitance $(1 \mathrm{kHz})$ of the PZT plate.

Uchiki et al. [2] presented a simplified solution for the fin's lateral movement $(x)$ as a function of vibrator's vertical displacement $(z)$.

$$
x(z)=\frac{1}{\tan \theta} z .
$$

The angular velocity $\omega_{r}[\mathrm{rad} / \mathrm{s}]$ of the rotor can be presented by the fin displacement $(x)$, fin-stator contact ra- dius $\left(r_{r}\right)$, and driving frequency $(f)$ with the following formula:

$$
\omega_{r}=\frac{x(z)}{r_{r}} f
$$

The torque of the motor can be represented as:

$$
T_{m}=F_{\mu} r_{r}=\mu F_{a} r_{r}
$$

where $F_{\mu}$ is a tangential component of the frictional force, $F_{a}$ is the axial force on the rotor, and $\mu$ is the static coefficient of friction.

The efficiency of the device can be evaluated as the ratio of the electrical power input to mechanical power output:

$$
\mu=\frac{P_{\mathrm{out}}}{P_{\mathrm{in}}}=\frac{T_{m} \omega_{r}}{U_{\mathrm{in}} I_{\mathrm{in}} \cos (\varphi)},
$$

where $U_{\text {in }}$ and $I_{\text {in }}$ are rms voltage and current supplied to motor. $\operatorname{Cos}(\varphi)$ is the power factor where $\varphi$ is phase difference between the voltage and current signals. The input current can be calculated from the supply voltage and the impedance characteristics $\left(I_{\text {in }}=U_{\text {in }} / Z\right)$.

In order to understand which frequencies transmit the electrical energy to mechanical vibration, it is important to analyze the frequency spectrum of the device. The ratio of energy stored in mechanical form (electrical energy converted to mechanical energy) to the total energy provided by the source (electrical energy) is represented by the electromechanical coupling coefficient ( $k_{\text {eff }}$ ), which can be calculated using the well-known relation between resonance $\left(f_{m}\right)$ and antiresonance $\left(f_{n}\right)$ frequencies [8]:

$$
k_{\mathrm{eff}}^{2}=\frac{f_{n}^{2}-f_{m}^{2}}{f_{n}^{2}} .
$$

The sharpness of the resonance is described by the Qfactor. The smaller the internal losses are in the piezoelectric element/device the higher the Q-factor. This means both a more efficient electromechanical interface and a narrower operational bandwidth. It is known that Q-factor of the piezoelectric devices can be evaluated from impedance characteristics [9]:

$$
Q_{m}=\frac{f_{r}}{f_{2}-f_{1}}
$$

where $f_{r}$ is a resonance frequency. The $f_{1}$ and $f_{2}$ are frequencies $3 \mathrm{~dB}$ off the amplitude of the resonance frequency $\left(f_{r}\right)$. The mechanical loss factor can be calculated from the Q-factor $\left(\zeta=1 / Q_{m}\right)[10]$.

\section{Finite Element Modeling}

Finite element harmonic and modal analyses of the cymbal, PZT plate, and stator were performed using ANSYS 5.7.1 ${ }^{\circledR}$ (ANSYS, Inc., Canonsburg, PA) to establish which vibration modes were active at any operational frequency and their operational characteristics. Absolute displacements and blocking forces were evaluated 


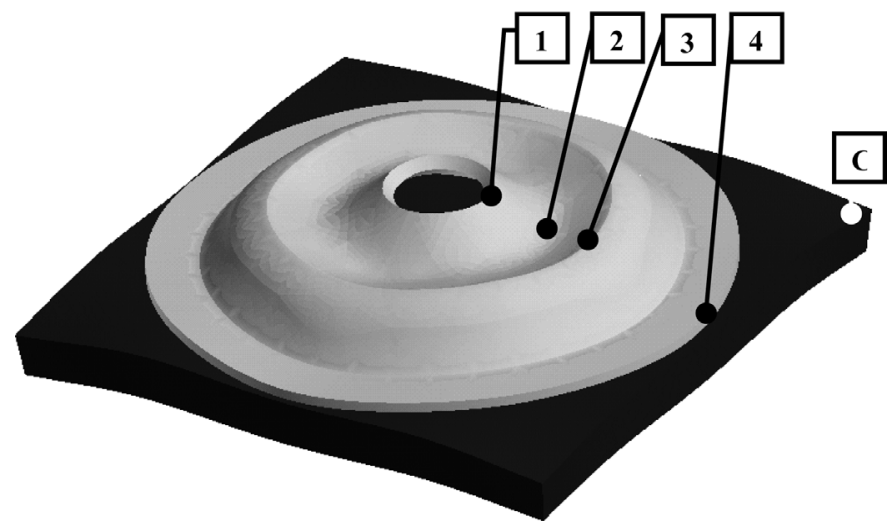

Fig. 3. Modeled resonance mode ( $Z$ displacement) for stator $(79.7 \mathrm{kHz})$. By way of explanation, in this mode, the rim of the hole at 1 is moving in the opposite direction to the locus of points at $r_{r}$ 2), where the rotor legs contact the cymbal. At this time in the motion, the corners, $\mathrm{C}$, of the ceramic plate tend to move down.

using harmonic analysis. Modeling was conducted in threedimensional (3-D) as it is not possible to model a square plate using radial symmetry, as was done in previous modeling work of cymbals [3].

The chosen step size in the analysis was $1 \mathrm{kHz}$, which gave a reasonable compromise for accuracy versus computational time. The effects of the bonding layer between the cymbal and PZT plate were neglected. As mechanical boundary conditions, the center of the PZT plate was fixed in the area located in its center point with a radius of $3 \mathrm{~mm}$, which was equivalent to the device mount in a test part (Fig. 2). The electric field was applied onto the top face of the PZT plate (i.e., cymbal side) and the bottom face was grounded. Orientation of the poling was in the thickness direction. The cymbal was defined as being made from an isotropic metallic material without any electrical resistance. The modeled total mass of the stator $(11.6 \mathrm{~g})$ compares very well with the measured mass of the test part presented in Table I, which verifies the geometry and material densities. The detailed material data for the PZT used (PC4, Morgan Electroceramic ${ }^{\mathrm{TM}}$ ) was taken from the manufacturer's datasheet [9] and from the PZT-4 data in [11].

Harmonic analysis of the plate and stator were carried out to locate the electrical resonances of the structure. Modal analysis was used to visualize mode shapes. Both were compared with the experimental data, as will be described below. Harmonic analysis demonstrated that the PZT plate described in Table I has a very clear resonant peak at $77.0 \mathrm{kHz}$ with a weaker one at $112.0 \mathrm{kHz}$. The stator has several piezoelectrically active resonant frequencies in the range $50-120 \mathrm{kHz}$. The strongest resonance of these was detected at $80.0 \mathrm{kHz}$. The detailed results of these analyses are discussed below and compared with experiment.

A modal analysis was carried out close to the resonant frequencies in order to establish an understanding of the relevant mechanical motion. Fig. 3 represents the mode shape $79.7 \mathrm{kHz}$. The mode shape at $61.5 \mathrm{kHz}$ is quite sim- ilar to this. The former is close to the plate's contour resonance frequency $(77 \mathrm{kHz})$, in which all the sides of the PZT plate are moving laterally in and out in the same phase.

A modal analysis also was carried out on the cymbal alone to compare its mechanical resonances with those observed in the electrical resonance of the complete stator. The radial symmetric resonance frequencies found for the cymbal were 53.4 and $78.3 \mathrm{kHz}$. Both of the mode shapes are virtually the same as in the modeled stator structure.

Harmonic analysis was used to get absolute values of displacement and blocking force at the rotor/stator contact-point $\left(r_{r}\right)$ (Fig. 2). The absolute values of vertical displacements were evaluated in four different measurement points (Fig. 3). The blocking force was evaluated by fixing measurement point 2 along the z-axis, which is equivalent to radius of contact point $\left(r_{r}\right)$. Table II presents the results achieved at two resonant frequencies when voltage $V_{p 0}=60 \mathrm{~V}$ was applied to the PZT plate. The mechanical damping factor $(\zeta)$ in the model was evaluated from the measured impedance characteristics (6).

The calculated displacements show how strongly the different points are deflected relative to each other. Displacement amplification $\left(Z_{2} / X_{4}\right)$ for 61 and $80 \mathrm{kHz}$ are 37 and 4 , respectively. One can notice that the resonance frequency is shifted a bit higher when obtaining the blocking force. This is due to the change in the mechanical boundary conditions, which were applied to the measurement point 2 (Fig. 3). When considering the current (I), it can be seen that it is much higher at the PZT plate's fundamental frequency, as would be expected. This leads to the maximum power input requirement. At the same time, the electromechanical coupling is greatest based on the achieved $k_{\text {eff }}$ values $\left(k_{\text {eff }}(61 \mathrm{kHz})=0.18, k_{\text {eff }}(80 \mathrm{kHz})=0.27\right)$ (5). The analogy suggests that the stator should be driven at its fundamental resonance in order to provide maximum power output. However, because of the different mechanical damping factors $(\zeta(61 \mathrm{kHz})=0.0063$, $\zeta(80 \mathrm{kHz})=0.0085)$, the displacements and reactive forces remain very close to each other (Table II).

A simple 2-D modal analysis was used to determine the resonance frequencies for the fins used in the experiments (Table I). Analytical calculations [12] suggest that a fin with thickness $t_{r}=0.5 \mathrm{~mm}$ and length $l=1.5 \mathrm{~mm}$ has its first resonance frequency at about $143 \mathrm{kHz}$. However, a fin with dimensions of $t_{r}=0.25 \mathrm{~mm}$ and $l=3.5 \mathrm{~mm}$ has its first resonance frequency at about $13 \mathrm{kHz}$. The latter fin was modeled in finite element modeling (FEM) as a 2-D beam model with one end fixed. The modeling gave the first and second resonance frequencies, 12 and $81 \mathrm{kHz}$. It can be seen that the latter is very close to the stator's resonance frequency $(80 \mathrm{kHz})$. This may cause a phase shift between the stator and fin movements and could mean that the fin is hitting the stator surface before or after it has finished its displacement cycle. This could generate increased wear at the point of contact and low-frequency components of vibration, which could be detected as an audible noise. 
TABLE II

Calculated Displacements, Blocking Forces, and Currents at the Stator's Resonance Frequencies.

\begin{tabular}{ccccccccccc}
\hline \multicolumn{7}{c}{ Displacement measurements } & & \multicolumn{3}{c}{ Force measurements } \\
\hline $\begin{array}{c}\text { Freq } \\
{[\mathrm{kHz}]}\end{array}$ & $\begin{array}{c}Z_{1} \\
{[\mu \mathrm{m}]}\end{array}$ & $\begin{array}{c}Z_{2}^{1} \\
{[\mu \mathrm{m}]}\end{array}$ & $\begin{array}{c}Z_{3} \\
{[\mu \mathrm{m}]}\end{array}$ & $\begin{array}{c}Z_{4} \\
{[\mu \mathrm{m}]}\end{array}$ & $\begin{array}{c}X_{4} \\
{[\mu \mathrm{m}]}\end{array}$ & $\begin{array}{c}\mathrm{I} \\
{[\mathrm{mA}]}\end{array}$ & & $\begin{array}{c}\text { Freq } \\
{[\mathrm{kHz}]}\end{array}$ & $\begin{array}{c}F^{\perp} \\
{[\mathrm{N}]}\end{array}$ & $\begin{array}{c}\mathrm{I} \\
{[\mathrm{mA}]}\end{array}$ \\
\hline 61 & 5.1 & -2.2 & -1.1 & 0.9 & 0.06 & 7.5 & & 62 & 5.8 & 117 \\
80 & 2.0 & -1 & 0.5 & -0.08 & -0.25 & 450 & & 81 & 5.8 & 300 \\
\hline
\end{tabular}

${ }^{1} Z_{2}$ and $F$ are z-displacement and blocking force at $r_{r}$, respectively.

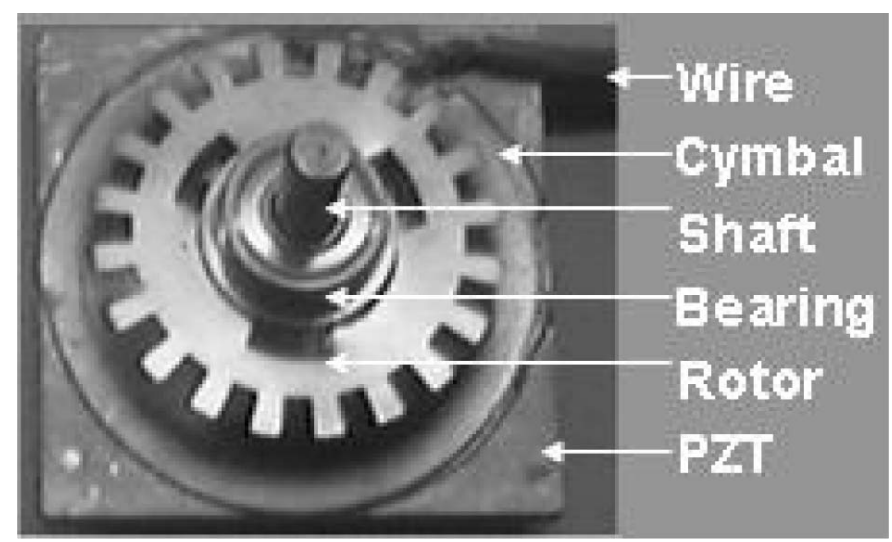

Fig. 4. Practical flextensional motor with stator, rotor, and electrical connections.

\section{Motor Construction}

The top view of a complete motor with the stator and rotor is presented in Fig. 4. An active element for the stator (PZT plate) was cut to the desired dimensions. The amplifier element was made from 0.45 -mm thick beryllium copper foil $(\mathrm{Cu} 98 / \mathrm{Be} 2)$ using a pressing tool. These two parts then were bonded together with electrically conductive epoxy (CircuitWorks ${ }^{\circledR}$ CW2400, Chemtronics, Kennesaw, GA) in order to provide electrical connection between the cymbal and PZT. The parts were held together at a temperature of $40^{\circ} \mathrm{C}$ for several hours, then cooled down before testing. In addition, electric wires were bonded to the cymbal and PZT with the same conductive epoxy. The top surface of the device mount was bonded with the Loctite ${ }^{\circledR}$ 402 cyanoacrylate adhesive (Henkel Consumer Adhesives, Inc., Avon, OH) to the center of the plate (Fig. 2). The lower surface of the device mount was connected to the external test jig.

All of the rotors were wet-chemically etched from the same material as the amplifier. The outside diameter of the rotor is $20 \mathrm{~mm}$, including the encoder features in its outer radius. The ball bearing was bonded with Loctite ${ }^{\circledR}$ 402 along the rotor's center axis using a centering tool. Fins were bent to the desired angle under a video microscope using a bending tool with a resolution of $\pm 1^{\circ}$. Mechanical dimensions were measured using a precision micrometer and weights with a Sartorius 1474 (Sartorius AG, Goettingen, Germany) micro-balance. Low-frequency capacitance (C @ $1 \mathrm{kHz}$ ) was measured using a GR1689M RLC DigiBridge (IET Labs, Inc., Westbury, NY).

\section{Stator Characterization}

The impedance characteristics of the PZT (PC4) plate alone and a complete stator were evaluated up to $120 \mathrm{kHz}$ at an alternating current (AC) electric field of $1 \mathrm{~V}_{r m s}$, with step size of $0.5 \mathrm{kHz}$ using a HP4192A (Agilent Technologies, Palo Alto, CA) impedance analyzer connected to a computer via GPIB interface. The PZT plate was connected between spring-loaded leads at its center point. The stator was measured in a test jig in which the stator's edge was installed between two spring-loaded leads.

In addition to the electrical measurements, the mechanical displacement of the stator was evaluated directly using a Polytec dual-beam differential laser Doppler vibrometer (Polytec OFV 3001, Polytec GmbH, Waldbronn, Germany) [13]. The stator was mounted in a precision microstage, which allowed scanning of sample points along one axis across the stator at millimeter intervals. A digital signal processing lock-in amplifier was used as a signal source for a power amplifier (Krohn-Hite 7500, Krohn-Hite Corp., Brockton, MA). The electric current was monitored by a noncontact current probe (Tektronix 6021, Tektronix, Beaverton, OR) and temperature inside the cymbal by a thermocouple.

\section{Motor Characterization}

In mechanical characterization, several rotors (Table I) with different fin lengths and inclinations were tested in order to investigate the influence that these parameters have on motor performance. Motor performance data were collected using a mechanical test jig designed to allow continuous measurement of the output torque and speed. The torque was monitored using a pulley-brake method and speed by integrated rotary encoder. Detailed description of the measurement setup can be found in [14]. The pulleybrake principle has been demonstrated in the micro newton meter range with resolution of $1 \mu \mathrm{Nm}$ and relative error of about $7.5 \%$ [15].

\section{Results And Discussion}

\section{A. Stator}

The measured impedance characteristics from 50 to $120 \mathrm{kHz}$ for the PZT (PC4) plate and complete stator 


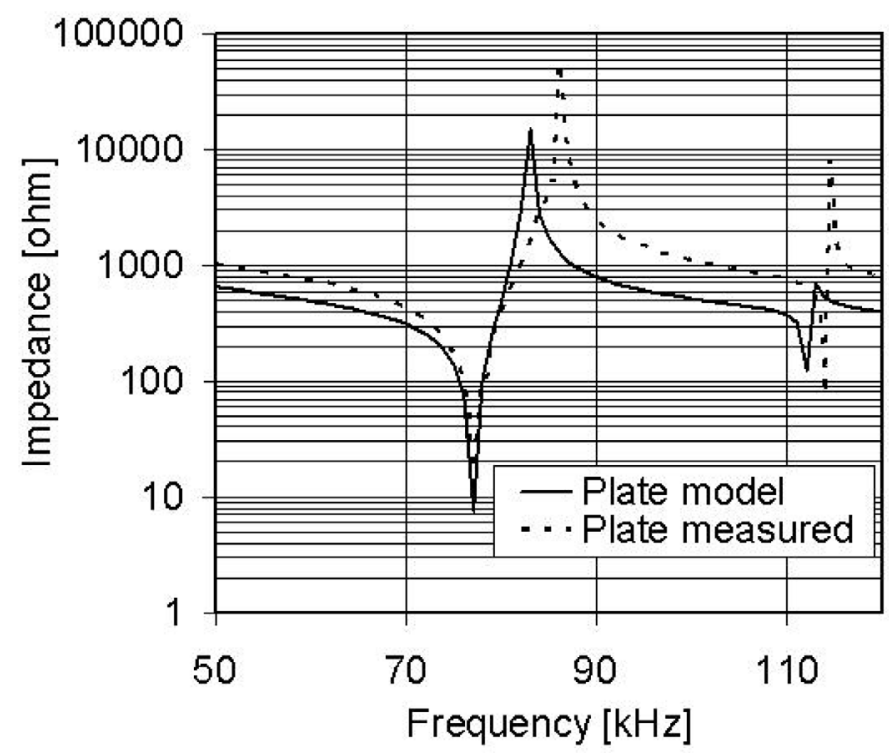

Fig. 5. Modeled and measured impedance characteristics of PZT plate $(\mathrm{PC} 4)$.

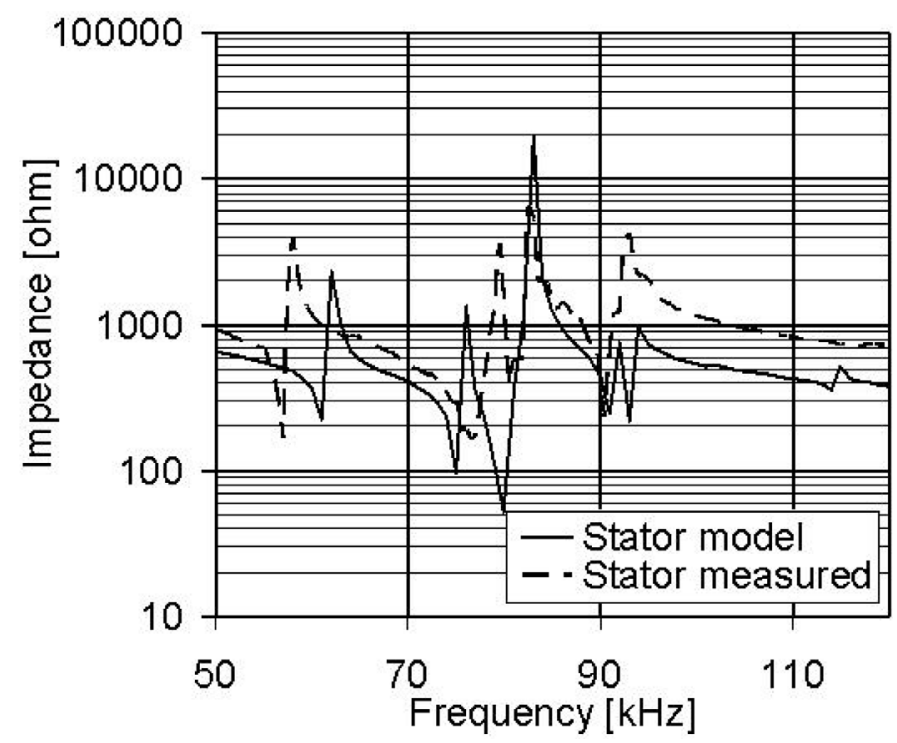

Fig. 6. Modeled and measured impedance characteristics of the complete stator structure (cymbal+PZT plate).

are presented in Figs. 5 and 6 , respectively. Comparison with the calculated impedance characteristics shows good agreement between the modeled and measured resonance characteristics. The interaction between the natural resonance frequency of PZT plate and cymbal gives split resonant impedance characteristics in the region of $80 \mathrm{kHz}$, which was predicted by FEM analysis and can be seen clearly from the graph (Fig. 6).

When comparing the results of harmonic analyses of the PZT plate (Fig. 5) and stator (Fig. 6), it is interesting to note the generation of a new resonant peak in the region of $60 \mathrm{kHz}$, which is not visible in the PZT plate alone. An upshift of the modeled $53.4 \mathrm{kHz}$ radial symmetric resonance of the cymbal to $61 \mathrm{kHz}$ is the most likely explanation for

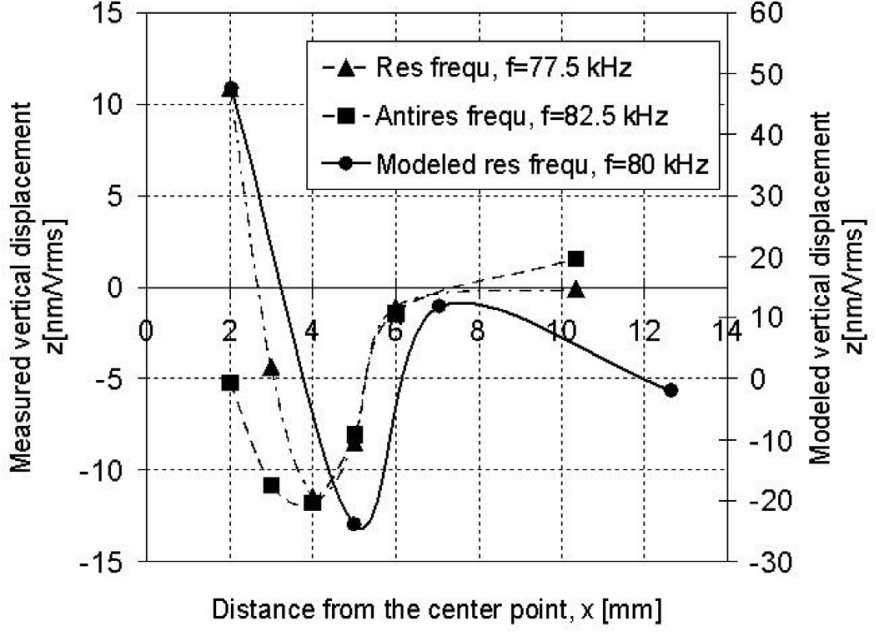

Fig. 7. Optically measured displacement values, 1 and 2, and modeled mode shape, 3 .

this, caused by the increase in cymbal stiffness due to the clamping of the ring as it is bonded to the piezoelectric plate. The shift in frequency cannot be seen at the higher frequency so strongly, because the natural frequency of the cymbal and stator are approximately the same. Instead of a frequency shift, the matching of the two natural frequencies can be detected from the ripple to the left of the mode at $80 \mathrm{kHz}$ (Fig. 6).

The optically measured stator displacement is presented in Fig. 7. The first line, 1, indicates the vibration shape after the stator reached a constant temperature. The stator was heated up to stable conditions $\left(\sim 109^{\circ} \mathrm{C}\right)$ with a supply voltage of $100 \mathrm{~V}_{p p}$. There the achieved phase measurements were stable and allowed definition of mode shape, which matched the modeled shape. Current $\mathrm{I}_{\text {in }}$ was measured as approximately of $420 \mathrm{~mA}_{r m s}$. The second line, 2 , illustrates vibration profile at antiresonance frequency $(82.5 \mathrm{kHz})$ and in stabilized temperature conditions that indicated a similar mode shape as was measured at the resonance frequency (line 1) but with smaller displacement values. In this case, the temperature stabilized to $\sim 45^{\circ} \mathrm{C}$, and the measured current was approximately $14 \mathrm{~mA}_{r m s}$. The third line, 3 , indicates the modeled vibration mode shape in resonance frequency. Modeled data points are based on the result of harmonic analysis described before (Table II). The relatively big differences between the modeled and measured displacements could be explained by the reduction of piezoelectric coefficient $d_{31}$ due to the heating up of the PZT element. The losses due to heat were neglected in the FEM model.

\section{B. Motor}

Fig. 8 shows the measured no-load speed characteristics of the flextensional motor as a function of leg inclination (Table I). In comparison, the calculated speed (2) using FEM (Table II) and interferometer measurement data (Fig. 7) are presented in parallel with the measurements. The practical device experiences a temperature rise due 


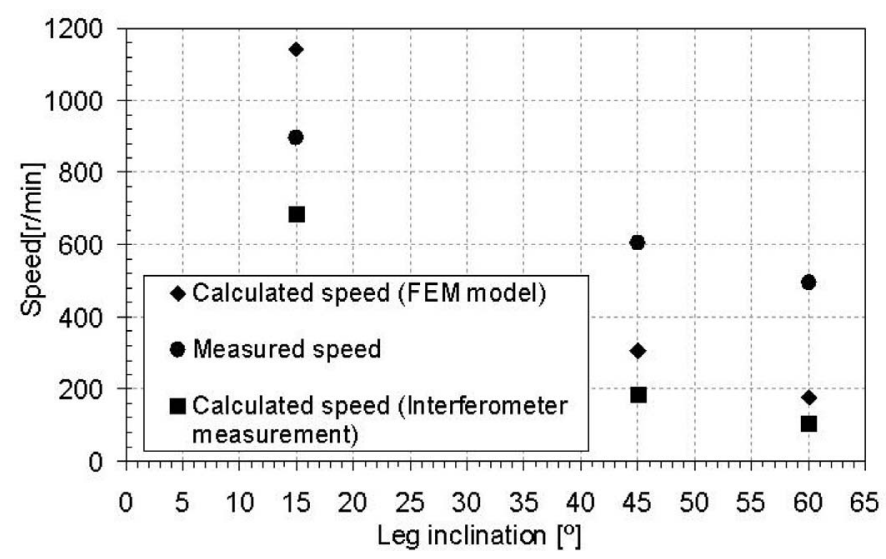

Fig. 8. Measured maximum no load speed as a function of leg inclination [rotors R2 $\left(\right.$ Freq $\left.=59.6 \mathrm{kHz}, F_{a}=1100 \mathrm{mN}, \theta=15^{\circ}\right)$, $\mathrm{R} 4\left(\right.$ Freq $\left.=69.4 \mathrm{kHz}, F_{a}=437 \mathrm{mN}, \theta=45^{\circ}\right), \mathrm{R} 6$ (Freq $=67 \mathrm{kHz}$, $\left.\left.F_{a}=213 \mathrm{mN}, \theta=60^{\circ}\right)\right]$. As a reference, the calculated maximum speeds based on FEM analysis at a frequency of $80 \mathrm{kHz}$ $\left(z_{\text {peak-peak }}=2 \mu \mathrm{m}\right)$ and interferometer measurement at a frequency of $80 \mathrm{kHz}\left(z_{\text {peak-peak }}=1.2 \mu \mathrm{m}\right)$.

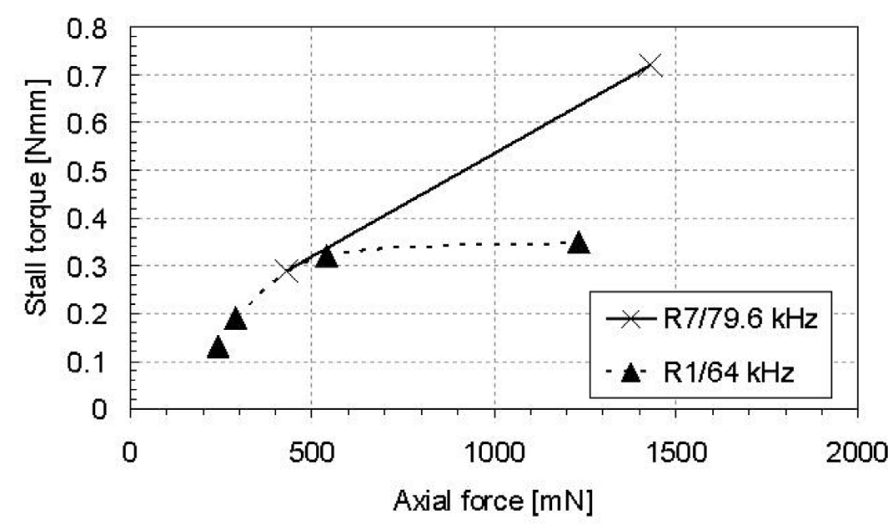

Fig. 9. Stall torque as a function of axial force $\left(\mathrm{R} 1\left(t_{r}=0.5 \mathrm{~mm}\right.\right.$ and $l=1.5 \mathrm{~mm}), \mathrm{R} 7\left(t_{r}=0.25 \mathrm{~mm}\right.$ and $\left.\left.l=3.5 \mathrm{~mm}\right)\right)$.

to the internal losses of the stator structure. In practical speed measurements, the motor was run for only $10 \mathrm{~s}$, and in the interferometer measurement the stator was excited for as long as 5 minutes before obtaining the results. The model suggests that the rotational speed should increase as the angle of inclination $\theta$ decreases. This is clearly shown in Fig. 8. It can be seen that the measured speed is located between two calculated speeds with the fin angle of $15^{\circ}$. With the angles $45^{\circ}$ and $60^{\circ}$, (1) is underestimating the achieved rotational speed. This shows that the angle of the fin is not that dominant parameter as the model assumes. The model also suggests that, when frequency increases, the speed should increase (2). However, Fig. 8 shows that the inclination of the fin has a more dominant influence on the speed characteristics.

Fig. 9 presents the stall torque characteristics of the motor. These results indicate that the stall torque is proportional to the applied axial force, which is in agreement with the model (3). The highest stall torque $0.72 \mathrm{Nmm}$ $\left(14 \mathrm{~N} \mu \mathrm{m} / \mathrm{V}_{r m s}\right)$ was achieved with rotor $\mathrm{R} 7$ at $79.6 \mathrm{kHz}$,

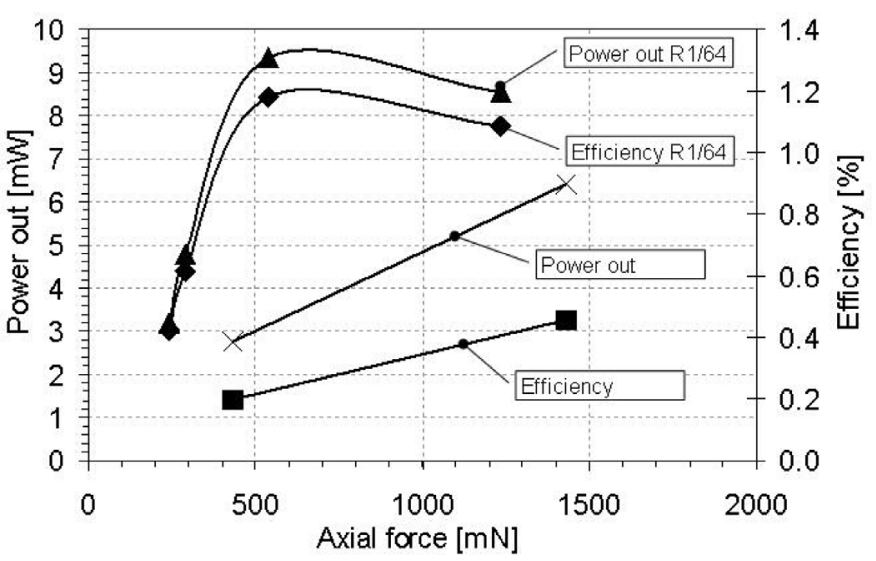

Fig. 10. Mechanical power output and efficiency as a function of axial force $\left(\mathrm{R} 1\left(t_{r}=0.5 \mathrm{~mm}\right.\right.$ and $\left.l=1.5 \mathrm{~mm}\right), \mathrm{R} 7\left(t_{r}=0.25 \mathrm{~mm}\right.$ and $l=3.5 \mathrm{~mm}))$.

which is close to the cymbal and plate natural frequencies. This compares with thickness mode elastic fin motor presented by Uchiki et al. [2], which achieved a maximum torque of $178 \mathrm{~N} \mu \mathrm{m} / \mathrm{V}_{r m s}$ but with much bigger PZT disc dimensions $(\varnothing=30 \mathrm{~mm}, t=14 \mathrm{~mm})$. The Uchiki's motor generates $18 \mathrm{Nnm} / \mathrm{V}_{r m s} / \mathrm{mm}^{3}$, and the flextensional motor generates $14 \mathrm{Nnm} / \mathrm{V}_{r m s} / \mathrm{mm}^{3}$, indicating that the smaller volume of PZT used in the flextensional structure largely accounts for the difference in performance. The drivable axial force values are approximately $20-25 \%$ of the modeled values, and this is an indication of energy losses such as heating. An increase in the frictional force will increase the stall torque, and this requires a higher mechanical force from the stator structure. This could be achieved by reducing the PZT thickness for a given, applied voltage. Another way to increase the torque is to increase the radius of the contact point $\left(r_{r}\right)$.

The mechanical power output and efficiency are presented in Fig. 10. The power output of $6.41 \mathrm{~mW}$ was achieved with the elastic rotor configuration $\left(t_{r}=0.25 \mathrm{~mm}\right.$ and $l=3.5 \mathrm{~mm}$ ) and at $79.6 \mathrm{kHz}$ with an axial force of $F_{a}=1430 \mathrm{mN}$. When driving the motor at $64 \mathrm{kHz}$ with the stiff rotor configuration $\left(t_{r}=0.5 \mathrm{~mm}\right.$ and $\left.l=1.5 \mathrm{~mm}\right)$, the maximum power output of $9.36 \mathrm{~mW}$ was achieved with axial force of $F_{a}=540 \mathrm{mN}$. This shows that the electrical energy at lower frequencies is translated more efficiently into the mechanical rotational energy. The loss of energy at high frequency might be explained by the structure's reduced mechanical response, which could be due to the inertia of leg bending. In addition, the second resonance frequency $\left(81 \mathrm{kHz}\right.$ ) of the elastic fin (rotor R7, $t_{r}=0.25 \mathrm{~mm}$ and $l=3.5 \mathrm{~mm}$ ) was very close to the driving frequency $(79.6 \mathrm{kHz})$, which may have resulted in loss of the power output. To be able to respond to the high-frequency displacements, the moving structure should be light and rigid. This suggests that the leg structure should be made either from a properly oriented composite network or some hollow construction providing lightweight and high stiffness in the bending direction. 
The efficiency of the motor was calculated as the ratio of the maximum mechanical output power and electrical input power (4). The highest efficiency was achieved at $64 \mathrm{kHz}$ with a stiff rotor structure $\left(t_{r}=0.5 \mathrm{~mm}\right.$ and $l=1.5 \mathrm{~mm})$. This combination had a maximum efficiency of $1.18 \%$ with $F_{a}=540 \mathrm{mN}, P_{\text {in }}=796 \mathrm{~mW}\left(\varphi=69^{\circ}\right.$, $\left.I_{\text {in }}=51 \mathrm{~mA}_{r m s}, U_{\text {in }}=49 \mathrm{~V}_{r m s}\right)$ and $P_{\text {out }}=9.36 \mathrm{~mW}$. The power input definition includes a compensation of electrical losses generated by the measuring electronics $(\sim 100 \mathrm{~mW})$. The achieved efficiency compares very well with other elastic fin designs and is in the upper range $(<1 \%$ [16], $<1.7 \%[7], 0.6 \%$ [2], 0.17\% [17]). It should be noted that the electric current in the driven frequency $(79.6 \mathrm{kHz})$ was very low $\left(\sim 65 \mathrm{~mA}_{r m s}\right)$ compared to the value determined in conjugation with vibrometer displacement measurements $\left(420 \mathrm{~mA}_{r m s}\right)$. This indicates that the motor was driven slightly out of resonance (between resonance and antiresonance).

The results suggest that the motor should be driven at a lower resonance mode rather than fundamental resonance of PZT plate. When driving the motor at the lower frequency $(64 \mathrm{kHz})$, the efficiency was higher compared to the high-frequency drive because of the higher electrical current intake at $79.6 \mathrm{kHz}$. Another reason might have been the rotor's reduced mechanical response with rotor R7, which was used in higher-frequency drive. Important factors that have been omitted and may significantly influence behavior are: sliding of the fin on the upstroke, which could cause significant loss of efficiency in this motor structure; a drift from resonance in the stator or a shift to a different resonant mode due to heating. The results from displacement measurements gave valuable information by confirming the modeled mode shape. Also it was important to notice in which temperature the stator stabilizes and its effect on phase measurements. From the point of view of efficiency, running the motor in antiresonance would be ideal because of lower power consumption. Probably, the most efficient running is found between the resonance and antiresonance frequencies. However, optimization of the running frequency would be a topic for further studies.

\section{CONCLUSIONS}

This paper has presented the design, fabrication, and characterization of a new type of standing wave piezoelectric ultrasonic motor. The motor uses a metallic cymbal to convert and amplify the contour mode vibrations of a square piezoelectric ceramic plate into flexural oscillations, which are further converted to produce rotary actuation by means of an elastic-fin friction. Displacement amplification is important in MEMS structures because the ratio between surface finish and device size is increased, which leads to higher frictional forces/losses in sliding medias. By amplifying the displacement of the PZT vibrator, the speed of the rotor can be increased. However, when the displacement is amplified, the generated force is decreased, which also decreases the achieved maximum torque compared to similar size of device run in thickness mode. In addition, the motor can be driven at a lower frequency than the same ceramic actuated in thickness mode, which makes fin design easier.

In particular, finite element analysis has been used effectively to demonstrate and characterize the vibrational modes of operation. The predicted mode shape was compared experimentally using a laser Doppler vibrometer. It was found that FEM calculations overestimated displacements of the cymbal because heating up of the PZT was neglected in the model. Some areas have been highlighted that should enable motor efficiency, torque, and speed to be improved. The best stall torque and no load speed for a 25 -mm square motor were $0.72 \mathrm{Nmm}$ and $895 \mathrm{r} /$ minute, respectively.

Future work will include analysis of a disc type flextensional motor and comparison in its operation to the square plate stator. In order to improve efficiency, it is important to develop system level models, including all key components such as stator, rotor, and spring with contact mechanics. Also very important is to update the FEM model to be able to take account heating of the PZT element as a function of excitation time and power input. Analyzing the motor as a system, and considering the heating-up effect, would explain which part of the motor loses the most of the energy and how it should be possible to increase efficiency.

\section{ACKNOWLEDGMENTS}

The authors wish to thank Dr. Tony Gee for his guidance and advice in performing the mechanical characterization, and Joe Southin for his expertise in finite element modeling. Funding from EPSRC under project number GR/N34017 and BAE Systems is gratefully acknowledged.

\section{REFERENCES}

[1] K. Uchino, Piezoelectric Actuators and Ultrasonic Motors. Norwell, MA: Kluwer Academic, 1997.

[2] T. Uchiki, T. Nakazawa, K. Nakamura, M. Kurosawa, and S. Ueha, "Ultrasonic motor utilizing elastic fin rotor," Jpn. J. Appl. Phys., vol. 30, pp. 2289-2291, Sep. 1991.

[3] A. Dogan, K. Uchino, and E. Newnham, "Composite piezoelectric transducer with truncated conical endcaps 'cymbal'," IEEE Trans. Ultrason., Ferroelect., Freq. Contr., vol. 44, pp. 597-605, May 1997.

[4] A. Dogan, J. F. Fernandez, K. Uchino, and R. E. Newnham, "The 'cymbal' electromechanical actuator," in Proc. IEEE Ultrason. Symp., vol. 1, 1996, pp. 213-216.

[5] P. J. Rayner and R. W. Whatmore, "Piezoelectric ultrasonic motor using flextensional amplification of a disc radial mode with elastic fin drive," in Proc. 9th US-Japan Seminar on Dielectric and Piezoelectric Ceramics, 1999, pp. 151-154.

[6] P. J. Rayner and R. W. Whatmore, "Ultrasonic motor," UK Patent No. GB 2,349,738.

[7] P. Rayner, "Piezoelectric ultrasonic motors and micromotors," Ph.D. dissertation, Cranfield University, Bedfordshire, UK, 2000.

[8] A. J. Moulson and J. M. Herbert, Electroceramics-Materials, Properties, Applications. London: Chapman \& Hall, 1990. 
[9] Piezoelectric Ceramic Products. Morgan Matroc Ltd., Unilator Division, UK.

[10] R. W. B. Stephens and A. E. Bate, Acoustics and Vibrational Physics. London: Edward Arnold, 1966.

[11] T. Ikeda, Fundamentals of Piezoelectricity. Oxford: Oxford Univ. Press, 1990.

[12] T. Sashida and T. Kenjo, An Introduction to Ultrasonic Motors. New York: Oxford Univ. Press, 1993.

[13] M. G. Cain and M. Stewart, "Measurement of the surface displacement in 1-3 piezo-composites," NPL Report MATC(A)94, Teddington, UK: National Physical Laboratory, Apr. 2002.

[14] J. T. Leinvuo, S. A. Wilson, R. W. Whatmore, and A. E. Gee, "Mesoscale piezo-motors: Scaling issues and performance measurement," in Proc. 17th Annu. Amer. Soc. Precision Engineering Meeting, CDROM, 2002.

[15] W. Brenner, G. Haddad, G. Popovic, A. Vujanic, G. Abraham, and A. Matzner, "The measurement of minimotors and micromotors torque characteristic," in Proc. IEEE Microelectronics, vol. 2, 1997, pp. 535-538.

[16] P. Muralt, "Ultrasonic micromotors based on PZT thin films," $J$. Electroceram., vol. 3, no. 2, pp. 143-150, 1999.

[17] M. Dubois and P. Muralt, "PZT thin film actuated elastic fin micromotor," IEEE Trans. Ultrason., Ferroelect., Freq. Contr., vol. 45, pp. 1169-1177, Sep. 1998.

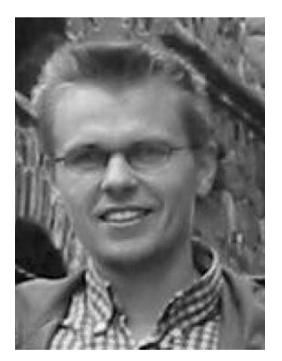

Joni Leinvuo was born in Helsinki, Finland, on April 1971. He received his B.S. degree in Mechanical Engineering (Machine Design) from Helsinki Institute of Technology in 1995 and M.S. degree in Mechanical Engineering (Mechatronics) from Helsinki University of Technology, Helsinki, Finland, in 2000. In October 2000 he enrolled as a Ph.D. degree candidate to Nanotechnology group at Cranfield University, Cranfield, UK. Mr. Leinvuo currently holds a position at VTI Technologies, Finland as a Sensor Design Engineer related to micro electro mechanical pressure sensors.

His research interest includes piezoelectric motors, micro-motors and MEMS.

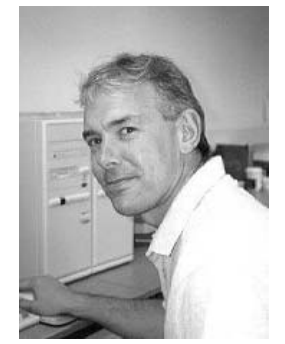

Stephen Wilson is a Senior Research Fellow in Advanced Materials at Cranfield University. He received a Ph.D. at Cranfield University for his thesis on "Electric Field Structuring of Piezoelectric Composites," which explored the use of moderately high electricfields during processing to induce anisotropic properties in ferroelectric ceramic/polymer composite materials. His study of materials processing parameters has been used to optimise the performance of piezoelectric sensor arrays for a real-time 3D ultrasound imaging system and his research interests are in piezoelectric micro-actuators, ultraprecision machining of ceramics, and dielectrophoresis. He is module coordinator and lectures on Microsystems Design.

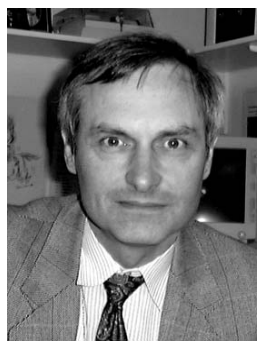

Roger W. Whatmore graduated with his Ph.D. degree in Physics from Cambridge University in 1977 and spent nearly twenty years working with the GEC Marconi (formerly Plessey) research laboratories at Caswell in the UK on the development and exploitation of ferroelectric materials in a wide range of electronic devices, particularly sensors and actuators, for which work he was awarded GEC's Nelson Gold Medal in 1993. In October 1994 he took the Royal Academy of Engineering Chair in Engineering Nanotechnology at Cranfield University, Cranfield, UK, where he is developing the use of ferroelectrics in microsystems and nanotechnology, particularly for sensors and actuators integrated onto silicon. He has published over 200 papers and 30 patents in the field. He was awarded the degree of Doctor of Science by Cambridge University in 2001. He is a Fellow of the Royal Academy of Engineering and a Fellow of the Institute of Materials, Minerals and Mining, who in June 2003 awarded him their Griffith Medal and Prize for Distinguished Work in Materials Science. 